OECD Green Growth Papers

2011-02

\title{
Interactions Between Emission Trading Systems and Other Overlapping Policy Instruments
}




\section{OECD GREEN GROWTH PAPERS}

The OECD Green Growth Strategy, launched in May 2011, provides concrete recommendations and measurement tools to support countries' efforts to achieve economic growth and development, while at the same time ensure that natural assets continue to provide the ecosystems services on which our well-being relies. The strategy proposes a flexible policy framework that can be tailored to different country circumstances and stages of development.

OECD Green Growth Papers complement the OECD Green Growth Studies series, and aim to stimulate discussion and analysis on specific topics and obtain feedback from interested audiences.

The papers are generally available only in their original language, English, with a summary in the other if available.

OECD Green Growth Papers are published on www.oecd-ilibrary and are also available at www.oecd.org/greengrowth

Please cite this paper as

Braathen, N. A. (2011), "Interactions Between Emission Trading Systems and Other Overlapping Policy Instruments", OECD Green Growth Papers, 2011-02, OECD Publishing, Paris. doi: 10.1787/5k97gk44c6vf-en

For further information, please contact

Nils Axel Braathen

Email: Nils-Axel.Braathen@oecd.org

(C) OECD 2011

Applications for permission to reproduce or translate all or part of this material should be made to: OECD Publishing, rights@oecd.org. 


\section{FOREWORD}

This paper discusses interactions that can occur when a cap-and-trade based emission trading system is combined with overlapping policy instruments (environmentally related taxes, subsidies, 'commandand-control regulations, information instruments, etc.), addressing emissions stemming from the same sources.

The paper is issued under the responsibility of the Secretary-General of the OECD.

Copyright OECD, 2011.

Applications for permission to reproduce or translate all or part of this material should be addressed to: Head of Publications Service, OECD, 2 rue André-Pascal, 75775 Paris Cedex 16, France. 
COM/ENV/EPOC/CTPA/CFA(2011)4/FINAL

\section{INTERACTIONS BETWEEN EMISSION TRADING SYSTEMS AND OTHER OVERLAPPING POLICY INSTRUMENTS}

\section{Introduction ${ }^{1}$}

1. The European Union introduced its cap-and-trade based Emission Trading System for $\mathrm{CO}_{2}$ emissions (EU ETS) in 2005, New Zealand enacted such a trading system in July 2010, ${ }^{2}$ and similar trading systems have been under serious political discussion in a number of other countries. Such trading systems can achieve important emission reductions in a cost-effective manner, and an important literature discusses their application. ${ }^{3}$

2. One of the characteristics of cap-and-trade systems, and environmentally related taxes, compared to most other instruments used for environmental policy is that they make the (marginal) costs of abating emissions explicit. While this in certain situations might be considered a disadvantage from a political point of view, it can also promote the formulation of environmental policies where the (marginal) costs and benefits balance reasonably well. ${ }^{4}$

3. However, parts of the literature in this area overlook the interactions that can take place between a cap-and-trade system and other policy instruments that address the same types of emissions from the same sources. ${ }^{5}$ When a cap is binding, this will determine the environmental outcome of the instrument mix directly, as long as it remains unchanged. Under these circumstances, adding other policy instruments will not cause further emission reductions, but would instead create room under the cap for other sources of emissions. However, they could facilitate a reduction of the cap, thereby lowering overall emissions. These points will be elaborated more below.

4. A number of the examples given in this paper concern instruments applied in conjunction with the EU ETS. It is, however, emphasised that the intention is not to 'single-out' this instrument for 'criticism'. On the contrary, a market-based ETS is an economically efficient way to reduce emissions. Rather, this paper explores the effects of other instruments in the presence of such a scheme. The points

Other recent papers discussing similar issues include Abrell and Weigt (2008); Böhringer, Koschel and Moslener (2008); Böhringer and Rosendahl (2009) and (2010); Congressional Budget Office (2009); De Jonghe et al. (2009); Duval (2008); Fischer and Preonas (2010); Johnstone (2003); Lehmann (2010); Levinson (2010); OECD (2009); Oikonomou and Jempa (2008); Pethig and Wittlich (2009); del Río González (2007); Sijm (2005); Sijm and van Dril (2003) and Unger and Ahlgren (2005).

2 See www.climatechange.govt.nz/emissions-trading-scheme/about/

3 See, for example, Weitzman (1974), Roberts and Spence (1976), Tietenberg (2006), OECD (2008) and Kaplow (2010).

$4 \quad$ This will of course also depend on the availability of estimates of the (marginal) damages caused by the emissions being addressed. Greenstone, Kopits and Wolverton (2011) describes recent estimates of the 'social costs of carbon' (SCC) elaborated by the Council of Economic Advisers and the Office of Management and Budget in the United States. For 2010, the central value of the SCC was found to be USD 21 per tonne of $\mathrm{CO}_{2}$ emissions.

$5 \quad$ For further discussion of instrument mixes for environmental policy more generally, see OECD (2007) and Braathen (2007). 
made here are generally valid when any instrument that places an effective 'cap' on the total emissions of certain types is in place - also instruments that could be significantly less cost-efficient than the EU ETS. ${ }^{6}$ The reason for the focus given here to the EU ETS is simply that it is one of the most important and beststudied of the relevant instruments. ${ }^{7}$

5. It is emphasised that the focus here is on emission categories where the environmental impacts are only related to the total amounts of emissions (e.g. $\mathrm{CO}_{2}$ ). If the environmental impacts also depend on e.g. where (some of) the emissions take place (as is the case for e.g. $\mathrm{SO}_{2}$ and $\mathrm{NO}_{\mathrm{x}}$ ), a cap-and-trade system will generally have to be combined with additional instruments. Adding more instruments could increase total costs - but it could also (significantly) increase total benefits. ${ }^{8}$

6. The paper is organised as follows: Section 2 discusses impacts of overlapping instruments in the short term - with the overall 'cap' being unchanged. Section 3 discusses the impacts 'additional' instruments can have on future caps, in the medium to long term. Section 4 draws some conclusions.

\section{Impacts in the short run; for a given cap}

\section{$2.1 \quad$ Impacts on $\mathrm{CO}_{2}$ emissions}

7. A natural starting point is to look more closely at the impact on $\mathrm{CO}_{2}$ emissions of combining a $\mathrm{CO}_{2}$-related cap-and-trade system with additional policy instruments that address such emissions from the same sources as the trading system. As already mentioned, doing so will not cause any extra emission reduction, as long as the cap of the trading system is binding ${ }^{9}$ and remains unchanged.

8. The 'additional' instrument(s) would indeed cause further abatement efforts by some emission sources, but - given the 'logic' of a cap-based trading system - this would lead to a reduction in permit prices and increased emissions from some other source(s) included in the trading system.

9. This point has important implications for the environmental effectiveness and economic efficiency of many policy instruments applied in countries with a cap-and-trade system in place, such as in all member countries of the EU. For example, given that the EU ETS among other things covers electricity generation, additional policy instruments that address electricity use ${ }^{10}$ or the $\mathrm{CO}_{2}$ emissions caused by electricity generation ${ }^{11}$ are unlikely to cut total $\mathrm{CO}_{2}$ emissions on an EU-wide scale so long as the cap is binding and is not itself reduced. For example, the ban on incandescent light bulbs in EU countries will, itself, have a limited impact on EU-wide $\mathrm{CO}_{2}$ emissions, in that the reduction in electricity consumption due to the higher energy efficiency of alternative lamps will trigger increased $\mathrm{CO}_{2}$ emissions somewhere else within the system. Likewise, other instruments used to reduce $\mathrm{CO}_{2}$ emissions in the industrial sources covered by the trading system will not cause overall $\mathrm{EU} \mathrm{CO}_{2}$ emissions to decrease.

In a so-called 'baseline-and-credits' trading system, total emissions are not decided in advance, and the points made in this paper are thus not generally valid.

The U.S. cap-and-trade system for $\mathrm{SO}_{2}$ emission allowances is also important and well-studied. However, for $\mathrm{SO}_{2}$, the environmental impacts depend not only on the total level of emissions, but also i.a. on where the emissions take place. Hence, a reduction in emissions in one place that is 'compensated' by increased emissions elsewhere could well lead to an improved net outcome for society.

$8 \quad$ See $e . g$. Johnstone (2003).

Section 2.5 addresses a situation where the ‘cap' is not binding.

E.g. measures to increase the energy-efficiency of electrical appliances and taxes on electricity use.

E.g. subsidies to promote market penetration of renewable energy sources, feed-in tariffs for renewables, and standards for the renewables content in electricity generation. 
10. For example, if country A spends EUR 100 million to subsidise the building of wind turbines to (partly) replace coal-fired power plants, this would certainly cause a reduction in $\mathrm{CO}_{2}$ emissions related to electricity generation in that country. This decrease in emissions would lower the demand of emission allowances in the EU ETS, causing the prices of these allowances to decrease and making it feasible for other firms covered by the system to emit more $\mathrm{CO}_{2}$. As long as the value of an emission allowance is positive, one or more of the other firms covered by the ETS will increase their emissions until the room under the cap is eliminated.

11. If country A really wanted to achieve a reduction in $\mathrm{CO}_{2}$ emissions at an EU (or global) level, it would be more effective to spend the EUR 100 million buying up emission allowances in the market and then never use them. That would guarantee a decrease in total emissions because, in effect, the cap on total emissions would be reduced. ${ }^{12}$

12. Favourable feed-in tariffs and 'green certificates' are other policy measures EU countries (and others) use to promote the development of renewable sources electricity. ${ }^{13}$ Again, such measures will not have an impact on EU-wide $\mathrm{CO}_{2}$ emissions, as long as the cap remains unchanged. When discussing a joint green certificates scheme for Norway and Sweden, Bye and Hoel (2009) characterised such certificates as "expensive and pointless renewable fun” [for policy makers].

13. Indeed, imposing measures in addition to a binding cap-and-trade system can lead to surprising and arguably perverse outcomes. For example, Böhringer and Rosendahl (2010) analysed a combination of a $\mathrm{CO}_{2}$ trading system (referred to as a 'black quota') and a green certificates system (referred to as a 'green quota'), and concluded that:

“... although the green quota further decreases total black power production, the dirtiest technology will actually increase output. The reason is that the green quota reduces the shadow cost of the emission constraint, mainly benefiting the most emission-intensive technologies.”

14. Fischer and Preonas (2010) addressed instrument mixes involving measures to promote renewable energy sources. They concluded that

"With overlapping policies (particularly inefficient ones), one can no longer point to allowance prices as an accurate reflection of marginal abatement costs. Nor are the benefits of other RES-E [Electricity from renewable energy sources] policies transparent. Consequently, as more tradable quota mechanisms are adopted, other pre-existing policies should be re-evaluated to ensure that taxpayers and consumers are still getting their money’s worth of the renewable energy they wish to support.”

15. In discussing the benefits of combining a cap-and-trade system with 'command-and-control' regulations, Levinson (2010) found that the

“... answer depends on whether the price of the tradable GHG emissions permits, and hence the marginal cost of compliance with the cap-and-trade legislation, is higher or lower than the marginal cost of compliance with the traditional regulatory standard. Intuitively, if the permit

12 However, by contributing to higher permit prices, this could have a negative impact on the setting of future 'caps', cf. the discussion below.

The (partly hidden) costs of some such estimates can be considerable. An OECD estimate indicates that if, with the feed-in tariffs applied until recently for photovoltaics in Italy, solar power were to achieve a market share of $5 \%$ of total electricity generation, then the average electricity bill would have to rise by some $30-35 \%$. 
price exceeds a firm's regulatory compliance costs, that firm would abate beyond the regulatory standard anyway, in response to the cap-and- trade incentives, and the regulatory standard would be irrelevant for that firm. By contrast, if the permit price falls below the regulatory compliance costs for a firm, the firm would meet the regulatory standard exactly and either sell excess permits or buy fewer than it would under cap-and-trade alone. The regulatory standard raises the firm's cost of abating emissions without any resulting increase in overall abatement.”

16. The US Congressional Budget Office (2009) wrote that

"If regulatory standards are applied [next to a cap-and-trade system], however, a different mix of technologies and products could occur than a cap-and-trade program would produce, especially if standards are relatively more stringent and more narrowly defined. Because the total reduction in emissions would be determined by the cap, the emissions would be the same as they would be without the standards. More of the reduction would be attributable to the standards, less would be achieved through the cap-and-trade program, and allowance prices would be lower."

17. In December 2009, the French Constitutional Court invalidated a "carbon tax" that the Parliament had adopted a few weeks earlier - in part because the tax would exempt firms that are covered by the EU ETS. Unfortunately, the Court does not seem to have understood that taxing those firms, while contributing to a reduction in their emissions, also would contribute to lowering the prices on emission allowances and increasing $\mathrm{CO}_{2}$ emissions elsewhere by a similar amount. Hence, a relatively well-designed "carbon tax" may have been scrapped, at least in part, owing to a misunderstanding of the economic effects of the measure on the part of the Constitutional Court.

18. A number of local and regional authorities have in recent years set their own $\mathrm{CO}_{2}$ emission reduction targets. For instance, the "Climate Change Action Plan" of London, established in March 2007, calls for a 60\% emission reduction from 1990 to 2025; New York’s “A Greener, Greater New York" campaign, set up in April 2007, aims for a 30\% reduction from 2005 to 2030, and Tokyo's "Climate Change Strategy", established in June 2007, seeks to achieve a 25\% reduction from 2000 to 2020 (CorfeeMorlot et al., 2009). While no binding nationwide $\mathrm{CO}_{2}$ emission reduction cap is covering New York and Tokyo at present, London is covered by the EU ETS. Hence, measures that London puts in place to reduce $\mathrm{CO}_{2}$ emissions in the sectors covered by the EU ETS would not lead to a reduction in EU-wide emissions, but would - like in the previous examples - be 'compensated' by increased emissions somewhere else in the EU.

19. Goulder and Stavins (2010) also addressed a similar issue and found that

"When the federal policy sets limits on aggregate emissions quantities, or allows manufacturers or facilities to average performance across states, the emission reductions accomplished by a subset of U.S. states may reduce pressure on the constraints posed by the federal policy, thereby freeing facilities or manufacturers to increase emissions in other states. This leads to serious "emissions leakage" and a loss of cost-effectiveness at the national level. ..."

20. The arguments above do not rest on an assumption that "all markets always work perfectly" which obviously would not have been realistic. There are certainly 'failures' in many of the markets covered by e.g. the EU ETS (imperfect competition, information failures, split incentives between landlords and tenants, etc.). But if the cap is binding, ${ }^{14}$ the workings of a trading system will 'automatically' lead to emission reductions in one place being countered by increased emissions from 
someone else covered by the system. A number of arguments that nevertheless can give a role for additional policy instruments are mentioned in Section 2.4.

21. There is a 'reverse side to the coin' presented above: Instruments that effectively bring new emissions in under the cap can contribute to net 'global' emission reductions.

22. For example, promoting the replacement of petrol- or diesel-driven vehicles by electric vehicles would lead to a net reduction in EU-wide $\mathrm{CO}_{2}$ emissions, regardless of the 'marginal' source of electricity within the EU. Because transport emissions are not presently covered by the ETS, measures to encourage their reduction could contribute to a reduction in EU-wide $\mathrm{CO}_{2}$ emissions. It is sometimes claimed that one needs to take into account the $\mathrm{CO}_{2}$ emissions caused in the generation of the electricity used by the electrical vehicles, but - as long as the total cap of the EU ETS is not increased - this is not correct. Such promotion would in fact cause emission reductions equal to the emissions the petrol- or diesel-driven vehicles would have caused - without any 'correction' related to $\mathrm{CO}_{2}$ emissions stemming from the necessary electricity generation. ${ }^{15} 16$

23. Similarly, a small but increasing number of ports are providing electricity to ships at berth, so that the ships can avoid using their auxiliary motors to produce electricity. ${ }^{17}$ This can contribute to reductions in emissions of $\mathrm{SO}_{2}, \mathrm{NO}_{\mathrm{x}}$ and particles, and in noise levels. In EU countries, providing shoreside electricity would also with certainty lead to a reduction in $\mathrm{CO}_{2}$ emissions - as long as the EU ETS cap remains unchanged - as otherwise unregulated emissions from the ships effectively would be brought in under the cap. ${ }^{18}$

\section{$2.2 \quad$ Impacts on energy security}

24. Even if the limited efficacy in relation to $\mathrm{CO}_{2}$ emissions of adding other policy instruments to a cap-and-trade system is accepted, it is sometimes contended that such measures are desirable on the basis that they improve the 'energy security' of a country or the wider region. For example, building wind turbines in EU countries is said to reduce the country's and the region's dependence on fossil fuel imports.

25. At first sight, this could seem correct. Wind turbines are driven by wind - not by coal, natural gas or fuel oil. However, interactions with the 'cap-and-trade' system again come into play. As explained above, replacing a coal- or gas-fired power plant with a wind turbine will necessarily increase $\mathrm{CO}_{2}$ emissions from some other source(s) covered by the trading scheme. And these $\mathrm{CO}_{2}$ emission-increases can only stem from increased use of fossil fuels among these 'other' sources. This could either be due to an increase in 'activity levels', ${ }^{19}$ or to an increase in the average $\mathrm{CO}_{2}$ intensity of a given activity level ${ }^{20}$ - or a

15 There are hence arguments for putting in place some policy instruments aiming to promote the replacement of petrol- and diesel-driven vehicles by electric vehicles. However, the measures applied for this purpose in some countries seem out of proportion to the benefits achieved. For example, ECON (2009) indicated that subsidies given to electrical vehicles in Norway exceed 2,500€ per tonne of $\mathrm{CO}_{2}$ abated.

For individuals in the EU that would like to 'do something themselves for the climate', replacing a petrolor diesel-driven car by an electric one could, hence, be an option. If the old car emitted 180 gram $\mathrm{CO}_{2}$ per $\mathrm{km}$, and it would be driven 200,000 km over its lifetime, 36 tonnes of $\mathrm{CO}_{2}$ would thus be avoided. But, if the price of an emission allowance in the EU ETS is EUR 15, a similar environmental impact could be obtained for EUR 540, by buying and cancelling 36 emission allowances.

See, for example, OECD (2010b), (2010c) and (2011a).

Emissions from international shipping are, however, not covered by countries' obligations under the Kyoto Protocol.

E.g. more fossil fuel-based power plants. 
combination of the two. Hence, 'overall fossil fuel use' (measured by the amount of $\mathrm{CO}_{2}$ emitted) in the EU ETS region as a whole would not be affected - as long as the cap is unchanged.

26. A caveat is that the 'supply risks' related to different fossil fuels could be (considered to be) different. If, for example, the supply of natural gas is considered more unsecure than the supply of coal, one might want to e.g. replace natural gas use in the electricity sector by wind turbines, and accept an increase in coal use in other electricity plants, or in various industrial sectors, instead.

27. The EU has decided that $20 \%$ of total energy consumption is to come from renewable resources by 2020 - in part with the objective of enhancing the energy security of the region. However, due to the operation of the $\mathrm{CO}_{2}$ cap under the ETS, this represents a moving target, which could prove to be very difficult and costly to meet. When one country takes action to comply with the obligation, the same country, or one of the other countries covered by the EU ETS, will automatically find it more difficult to reach the renewables target. This is because the fossil fuel replaced by a renewable energy source in one firm will largely be used somewhere else, within the ETS, as explained above. Hence, replacing e.g. a coal-fired power plant by a wind turbine park, or replacing fuel oil used in a paper mill by forest-based waste products, will free up $\mathrm{CO}_{2}$ allowances under the ETS cap, reducing their prices. The allowances will be used somewhere else - entailing increased fossil fuel use there. The total share of renewables in the energy mix - at the EU level - will thus not be much altered (and total energy use could in principle increase). A given country may reduce its dependence on imported fossil fuels by such measures - but this would largely be at the 'expense' of some other country.

28. Hence, there are environmental and economic reasons for EU authorities to review the relationship of the current renewables target to the $\mathrm{CO}_{2}$ cap.

\subsection{Impacts on other types of emissions / externalities}

29. Still another argument used to 'defend' the use of 'additional' instruments on top of a cap-andtrade scheme for $\mathrm{CO}_{2}$ emissions is that those instruments would also affect other types of emissions (e.g. emissions of $\mathrm{SO}_{2}, \mathrm{NO}_{\mathrm{x}}$ and particulate matter) stemming from the $\mathrm{CO}_{2}$ emission sources. At first sight, this seems probable, but closer analysis casts some doubts.

30. One point to make is that it would most likely be more effective and efficient to address such other emissions through policy instruments specially designed for that purpose, than to rely on ancillary benefits from instruments primarily designed to address $\mathrm{CO}_{2}$ emissions. ${ }^{21}$

31. More important in the present context is, however, that it is not given that there would be any net co-benefits stemming from the 'additional' instruments, when they are used on top of a cap-and-trade scheme. The reason is similar to the points made in the two preceding sub-sections: the 'additional' instruments would cause increased use of fossil fuels 'elsewhere' among the sources covered by the trading system. The net impact on e.g. $\mathrm{SO}_{2}, \mathrm{NO}_{\mathrm{x}}$ and particle emissions will, hence, depend on the relative emission intensities of the sources that reduce and the sources that increase their $\mathrm{CO}_{2}$ emissions.

32. Transport fuels are not covered by the EU ETS, but, in principle, one could include such fuels in a cap-and-trade system, for example by obliging petroleum refineries (and similar) to hold emission allowances covering the $\mathrm{CO}_{2}$ emissions that will be caused by the combustion of the fuels they sell. If this were the case, there would certainly be good reasons to apply additional instruments to address other

\footnotetext{
20 E.g. substitution of a coal-fired power plant for a gas-fired one.

21 This being said, co-benefits of climate change mitigation policies in general can certainly be important, cf. e.g. Bollen et al. (2009).
} 
externalities related to vehicle use (local air pollution, accidents, congestion, etc.) - but, as mentioned above, those instruments should primarily be designed with the intention of addressing the 'other' externalities, not come about as side-benefits of instruments primarily designed to address $\mathrm{CO}_{2}$ emissions.

\section{$2.4 \quad$ Impacts on economic efficiency}

33. In spite of the arguments presented in the preceding sub-sections, there are economic efficiency arguments for applying additional instruments on top of a 'cap-and-trade' system if they effectively address relevant market failures, such as information barriers, market power in relevant markets, split incentives between landlords and tenants, etc. Energy-labelling can reduce information barriers, stricter building codes can address split incentives between landlords and tenants, active competition policy and various regulations can limit market power, etc.

34. The Congressional Budget Office (2009) states that

"Although cap-and-trade programs by themselves are more cost-effective in general, combining regulatory standards with cap-and-trade programs can yield lower costs under some circumstances. Standards could contribute to a lower economy -wide cost of achieving a cap on emissions if the higher energy prices caused by the cap did not create sufficient incentives for businesses or consumers to reduce emissions cost-effectively.”

35. However, the additional instruments should (like any other policy instrument) be subject to a careful cost-benefit analysis, where (almost) no benefits should be assumed to stem from reduced emissions of $\mathrm{CO}_{2}$ or local air pollutants, or as regards an increase in energy security.

36. It is also well-known that there are positive externalities related to R\&D and technological innovation. Potential innovators will not be able to capture all the benefits of innovation for themselves, and in an unregulated economy, too few resources would hence be devoted to such activities. ${ }^{22}$ There are, hence, valid economic efficiency arguments for applying instruments to promote new technologies that help abate $\mathrm{CO}_{2}$ emissions, on top of a cap-and-trade system - also while the cap remains unchanged - if the expected benefits exceed the expected costs.

37. The conclusion of Abrell and Weigt (2008) quoted to above continues as follows:

"Learning effects are the standard justification of renewable energy support. Generally, it is agreed that there are learning effects for renewable generation technologies. Therefore, a uniform support scheme for renewable energies points into the right direction. However, differentiating such a system by technologies needs to be justified by different learning rates. However, these rates are generally unknown and hard to estimate. Therefore, an efficient differentiation seems to be impossible. Furthermore, if renewable support schemes are justified on the base of learning effects, then the same argument applies for other emerging technologies which are not renewable but supposed to have learning effects, like CCS technologies.”

38. Duval (2008) pointed to a particular market failure in relation to climate-related innovation: Given the potentially very large welfare consequences of any major breakthrough in technological progress, e.g. in the area of electricity production, [even] a strong protection of intellectual property rights may be insufficiently credible to private investors, who may expect governments to deprive them of any major innovation rent $a$ posteriori. This is an additional argument for public support for research in areas where one might see breakthrough climate-related innovations. 


\subsection{Impacts if the 'cap' is not binding}

39. As for any other policy instruments, there is a possibility that the 'cap' set for a cap-and-trade system will not be binding - meaning that it would be exceeded in practice, e.g. due to a lack of appropriate monitoring and enforcement. Another explanation for an un-binding cap could be that it is set so undemanding that already-under-way technical progress will ensure it is met anyway. Many of the interactions with overlapping instruments discussed above would in such cases not take place, as the emission reductions triggered by the 'additional' policy instruments would no longer automatically be 'compensated' by increased emissions somewhere else under the cap.

40. In such situations, overlapping instruments could in practice contribute to reduce overall emissions - acting as some sort of 'additional barriers' on the emissions.

41. However, in relation to the EU ETS in particular, 'cheating' in relation to the targets does not seem to have been a significant issue. This could in part be because the penalty for not holding allowances for all emissions is very high (EUR 100 - compared to an allowance price of about EUR 15 at present). The quite generous initial allocation of permits can also have contributed. In addition, the firms covered by schemes are relatively few, and relatively easy to monitor. The role of overlapping instruments hence seems more limited in this case.

\section{Impacts on future caps; in the medium to long term}

42. Having so far discussed the impacts of 'additional' instruments next to a given cap on $\mathrm{CO}_{2}$ emissions, it is also important to address the possible impacts of these instruments on the level of 'strictness' of the total cap in the future. Additional instruments certainly can create the conditions to tighten the cap in the future, but whether this actually occurs will depend on a range of factors, including the political economy conditions surrounding energy and climate policy in the medium to longer term.

43. A first case to consider is instruments meant to stimulate technological development, which also have an impact on current emission levels. ${ }^{23}$ Examples include feed-in tariffs for renewables, green certificates and emission standards for electrical appliances. Part of the rationale given for their use in conjunction with cap-and-trade schemes is that they could make it possible to set a stricter cap in the future. As explained above, such instruments will in the short to medium term reduce emissions from some of the capped sources, free up emission allowances, causing allowance prices to decrease and emissions to increase elsewhere within the capped system. The reduced allowance prices will (marginally) reduce the incentives for all other sources to develop new abatement technologies - the profitability of spending time and resources to develop such technologies will (marginally) be reduced.

44. The increase in emissions elsewhere will also mean that fewer abatement measures may be applied there in the short to medium term. Hence, among these other emission sources, there may be less "learning by doing”, hence (marginally) reducing their ability to innovate.

45. However, returning to 'additional' instruments more broadly - it is important how they can be expected to affect current and future allowance prices. ${ }^{24}$ The caps under EU's 20-20-20 decision were the

$23 \quad$ The points made here are not relevant for instruments that can cause technology development, without having a (significant) impact on current $\mathrm{CO}_{2}$ emissions, such as e.g. public subsidies for research in breakthrough technologies. If an instrument does not free up allowances in the short term, the "perverse" counter-effects mentioned in this paper will not materialise.

As Roberts and Spence (1976) pointed out, there are arguments for combining a trading system with a set of 'taxes'. If allowance prices were 'very low', a 'tax' could act as a floor on the 'carbon price'- providing a continued incentive to innovate. A guaranteed minimum carbon price - like recently proposed by the UK 
result of a political process, ${ }^{25}$ rather than being necessarily based on a detailed estimation of the related costs. However, it is quite possible that future caps will be 'endogenous', meaning that a new political deal at least partly will be based on assessments of the expected costs of achieving the respective targets.

46. An example of an emission cap having proven to be endogenous in practice can be found regarding the US $\mathrm{SO}_{2}$ allowance trading system. There, the total number of allowances was significantly reduced in response to lower-than-expected allowance prices, cf. e.g. Ellerman (2002).

47. If an additional policy instrument, on top of a trading system, effectively contributes to lowering current and/or expected future allowance prices, by helping to overcome current market failures in an efficient way, and/or by cost-effectively stimulating development of new abatement technologies, it could in fact contribute to the setting of a stricter cap for future years. If not, it would pull in the opposite direction.

48. From a political economy perspective, policy makers have not felt it feasible to tighten the cap of the EU ETS enough to raise the price of carbon emissions to the level that would cause technological change on the scale needed to address the threat of major climate changes. ${ }^{26}$ In such a situation, it can make sense to try to facilitate the setting of a stricter cap in the future by applying 'additional' instruments on top of the ETS - but it is important to assess both ex ante and ex post whether the additional instruments in practice can be expected to lower the cost of reducing the capped emissions (or in fact have done so).

\section{Conclusions}

49. To conclude: well designed emission trading systems are environmentally effective and economically efficient ${ }^{27}$ instruments to address emissions of $\mathrm{CO}_{2}$ and other greenhouse gases. The purpose of this note is not to question their usefulness. Once a 'cap-and-trade' system has been put in place, further emission reductions are, however, unlikely to be obtained by applying additional policy instruments to the same emissions from the same sources, as long as the cap is unchanged. If an additional instrument in practice contributes to reducing the costs of complying with the cap, it could, however, contribute to a

Government - can significantly reduce price-related uncertainty for potential investors that often have to plan large investments many years in advance. This could make it easier to realise investments needed to put countries on track for a low-carbon future. If instead allowance prices were 'very high', those obliged to hold emission allowances could have the option of instead paying a pre-determined 'tax' that would act as a ceiling on the allowance prices. (A 'reserve' of additional emission allowances that can be sold if prices increase too much could to some extent serve a similar function. This would limit the environmental uncertainty related to the provision, but increase the price uncertainty, as public authorities could run out of permits in the 'reserve'.) This 'tax' would, however, not be paid for emissions for which the emitter holds an allowance. However, 'capping' the allowance prices over a long period of time by putting in place a price "ceiling" could be inconsistent with the targeted emission reductions. See also Jacoby and Ellerman (2004), Strandlund (2009) and Burtraw, Palmer \& Kahn (2010).

In March 2007, the EU Heads of State and Government agreed a series of climate and energy targets to be met by 2020, known as the "20-20-20" targets. These are:

- A reduction in EU greenhouse gas emissions of at least 20\% below 1990 levels;

- $\quad 20 \%$ of EU energy consumption to come from renewable resources;

- A $20 \%$ reduction in primary energy use compared with projected levels, to be achieved by improving energy efficiency.

See http://ec.europa.eu/clima/policies/package/index_en.htm for further information.

The same comment could certainly be made regarding policy makers in other countries as well.

This is particularly the case if the permits are auctioned, and not handed out for free, cf. OECD (2008). 
stricter cap being set in the future - on the assumption that such considerations are taken into account when future 'caps' are set. ${ }^{28}$

50. Policy makers in countries with a 'cap-and-trade' system in place should consider carefully the actual contributions of any other policy instrument(s) they apply to address emissions from sources already covered by a binding 'cap'. There is a danger that some of them increase the total cost of reaching a given (environmental) outcome without making future reductions in the 'cap' more likely.

\section{REFERENCES}

Abrell, Jan and Hannes Weigt (2008), The Interaction of Emissions Trading and Renewable Energy Promotion, Economics of Global Warming, WP-EGW-05, Dresden University of Technology. www.janabrell.de/papers/abrell weigt interaction emission trading renewable support.pdf.

Böhringer, Christoph, Henrike Koschel and Ulf Moslener (2008), "Efficiency losses from overlapping regulation of EU carbon emissions”, Journal of Regulatory Economics, Vol. 33, pp. 299-317.

Böhringer, Christoph and Knut Einar Rosendahl (2009), Green serves the dirtiest. On the interaction between black and green quotas, Discussion Papers 581, Statistics Norway, Discussion Papers in Economics V-315-09, Oldenburg University, and CESifo Working Paper No. 2837.

Böhringer, Christoph and Knut Einar Rosendahl (2010), “Green Promotes the Dirtiest: On the Interaction between Black and Green Quotas in Energy Markets”, Journal of Regulatory Economics, Vol. 37, pp. 316-325.

Bollen, Johannes, Bruno Guay, Stéphanie Jamet and Jan Corfee-Morlot (2009), “Co-benefits of climate change mitigation policies: literature review and new results”, Economics Department Working Papers No. 693, OECD, Paris. Available at www.oecd.org/officialdocuments/displaydocumentpdf/?cote=eco/wkp(2009)34.

Braathen, Nils Axel (2007), "Instrument Mixes for Environmental Policy: How Many Stones Should be Used to Kill a Bird?”, International Review of Environmental and Resource Economics, Vol. 1, pp. 185-235.

Burtraw, Dallas, Karen Palmer and Danny Kahn (2010), “A symmetric safety valve”, Energy Policy, Vol. 38, pp. 4921-4932.

Bye, Torstein and Michael Hoel (2009), “Green certificates - expensive and pointless renewable fun”, English translation of an article in Samfunnsøkonomen nr. 7, 2009. Available at www.ssb.no/english/research/articles/2009/12/1259932098.4.html.

Congressional Budget Office (2009), How Regulatory Standards Can Affect a Cap-and-Trade Program for Greenhouse Gases, Congressional Budget Office, Washington, D.C. Available at www.cbo.gov/ftpdocs/105xx/doc10562/09-16-CapandStandards.pdf. 
Corfee-Morlot, Jan, et al. (2009), “Cities, Climate Change and Multilevel Governance”, OECD Environmental Working Papers No.14, OCED, Paris. Available at www.oecd.org/dataoecd/10/1/44242293.pdf.

De Jonghe, Cedric et al. (2009), "Interactions between Measures for the Support of Electricity from Renewable Energy Sources and $\mathrm{CO}_{2}$ Mitigation.” Energy Policy, Vol. 37, pp. 4743-4752.

Duval, Romain (2008), “A Taxonomy of Instruments to Reduce Greenhouse Gas Emissions and their Interactions”, OECD Economics Department Working Papers, No. 636, OECD Publishing. http://dx.doi.org/10.1787/236846121450.

ECON (2009), Virkemidler for introduksjon av el- og hybridbiler (Policy measures for introduction of electrical and hybrid vehicles) (in Norwegian). Report prepared for the Norwegian Petroleum Institute, Econ Pöyry, Oslo. Available at http://np.nsp01cp.nhosp.no/getfile.php/Filer/Tema/Miljo/Virkemidler\%20for\%20introduksjon\%20a v\%20el-\%20og\%20hybridbiler\%20okt09.pdf.

Ellerman, A. Denny (2002), Analysis of the Bush Proposal to Reduce the $\mathrm{SO}_{2}$ Cap. Working Paper 2002002 of the Center for Energy and Environmental Policy Research, MIT. Available at http://web.mit.edu/ceepr/www/publications/workingpapers/2002-002.pdf.

Fischer, Carolyn and Louis Preonas (2010), “Combining Policies for Renewable Energy: Is the Whole Less Than the Sum of Its Parts?”, International Review of Environmental and Resource Economics, Vol. 4, pp. 51-92.

Goulder, Lawrence H. and Robert N. Stavins (2010), Interactions between State and Federal Climate Change Policies, NBER Working Paper 16123, National Bureau of Environmental Research, Washington D.C. See www.nber.org/papers/w16123.

Greenstone, Michael, Elizabeth Kopits and Ann Wolverton (2011), Estimating the Social Cost of Carbon for Use in U.S. Federal Rulemakings: A Summary and Interpretation, NBER Working Paper No. 16913, National Bureau of Economic Research, Washington, D.C. See www.nber.org/papers/w16913.

Jacoby, Henry D. and A. Danny Ellerman (2004), “The safety valve and climate policy”, Energy Policy, Vol. 32, pp. 481-491.

Johnstone, Nick (2003), Tradable Permits and Other Environmental Policy Instruments - Killing one Bird with two Stones, CESifo Forum 1 / 2003, Ifo Institute for Economic Research, Munich. See www.cesifo-group.de/portal/page/portal/DocBase Content/ZS/ZS-CESifo Forum/zs-for-2003/zsfor-2003-1/forum1-03-focus.pdf.

Kaplow, Louis (2010), Taxes, permits and climate change, Discussion Paper No. 675, Harvard Law School, available at www.law.harvard.edu/programs/olin_center/papers/pdf/Kaplow_675.pdf.

Lehmann, Paul (2010), "Justifying a Policy Mix for Pollution Control: A Review of Economic Literature”, Journal of Economic Surveys, DOI: http://10.1111/j.1467-6419.2010.00628.x.

Levinson, Arik (2010), “Interactions Among Climate Policy Regulations”, NBER Working Paper 16109, National Bureau of Economic Research, Washington, D.C., www.nber.org/papers/w16109

OECD (2007), Instrument Mixes for Environmental Policy, OECD, Paris. See www.oecd.org/env/policies/mixes.

OECD (2008), Environmentally Related Taxes and Tradable Permit Systems in Practice, OECD, Paris. Available at www.oecd.org/officialdocuments/displaydocumentpdf?cote=COM/ENV/EPOC/CTPA/CFA(2007)3 1/FINAL. 
OECD (2009), The Economics of Climate Change Mitigation: Policies and Options for Global Action Beyond 2012, OECD, Paris. www.oecd.org/document/56/0,3746,en_2649_34361_43705336_1_1_1_1,00.html.

OECD (2010a), Taxation, Innovation and the Environment, OECD, Paris. See www.oecd.org/env/taxes/innovation.

OECD (2010b), Environmental impacts of international shipping: A case study of the port of Rotterdam, OECD, Paris. Available at www.oecd.org/officialdocuments/displaydocumentpdf?cote=env/epoc/wpnep/t(2009)6/final.

OECD (2010c), Environmental impacts of international shipping - The role of ports: Case study of the ports of Los Angeles and Long Beach. OECD, Paris. Available at www.oecd.org/officialdocuments/displaydocumentpdf?cote=env/epoc/wpnep/t(2009)5/final.

OECD (2010d), The OECD Innovation Strategy: Getting a Head Start on Tomorrow, OECD, Paris. Available at www.oecd.org/document/15/0,3746,en_2649_34273_45154895_1_1_1_1,00.html.

OECD (2011a), Environmental impacts of international shipping - The role of ports: Synthesis report. OECD, Paris. Available at www.oecd-ilibrary.org/environment/environmental-impacts-ofinternational-shipping 9789264097339-en.

OECD (2011b), Green Growth Strategy Synthesis Report, C(2011)29REV1.

Oikonomou, Vlasis and Catrinus J. Jepma (2008), “A Framework on Interactions of Climate and Energy Policy Instruments”, Mitigation and Adaptation Strategies for Global Change, Vol. 13, pp. 131-156.

Pethig, Rüdiger and Christian Wittlich (2009), "Interaction of Carbon Reduction and Green Energy Promotion in a Small Fossil-Fuel Importing Economy”. CESifoWorking Paper Series, No. 2749. CESifo Group, Munich. Available at www.ifo.de/pls/guestci/download/CESifo\%20Working\%20Papers\%202009/CESifo\%20Working\%2 0Papers\%20August\%202009/cesifo1_wp2749.pdf.

del Río González, Pablo (2007), "The Interaction between Emissions Trading and Renewable Electricity Support Schemes. An Overview of the Literature”, Mitigation and Adaptation Strategies for Global Change, Vol. 12, pp. 1363-1390.

Roberts, Marc J., and Michael Spence (1976), “Effluent Charges and Licenses under Uncertainty.” Journal of Public Economics, Vol. 5, pp. 193-208.

Sijm, Jos (2005), "The interaction between the EU emissions trading scheme and national energy policies”, Climate Policy, Vol. 5, pp. 79-96.

Sijm, Jos and A.W.N van Dril (2003), The Interaction between the EU Emissions Trading Scheme and Energy Policy Instruments in the Netherlands. Report prepared as part of the European Commission's project Interaction in EU Climate Policy. Available at www.ecn.nl/docs/library/report/2003/c03060.pdf.

Strandlund, John K. (2009), A Safety Valve for Emissions Trading, University of Massachusetts Amherst, Department of Resource Economics Working Paper No. 2009-4, See www.umass.edu/resec/workingpapers.

Tietenberg, Tom H. (2006), Emission Trading: Principles and practice. Second edition. Resources for the Future, Washington D.C.

Unger, Thomas, and Erik O. Ahlgren (2005), "Impacts of a common green certificate market on electricity and $\mathrm{CO}_{2}$ emission markets in the Nordic countries”, Energy Policy, Vol. 33, pp. 2152-2163.

Weitzman, Martin L. (1974) “Prices vs. Quantities”, Review of Economic Studies, Vol. 4, pp. 477-491. 
www.oecd.org/greengrowth 